\title{
Bioactivity of miltefosine against aquatic stages of Schistosoma mansoni, Schistosoma haematobium and their snail hosts, supported by scanning electron microscopy
}

\author{
Maha M Eissa ${ }^{1 *}$, Samia El Bardicy ${ }^{2}$ and Menerva Tadros ${ }^{2}$
}

\begin{abstract}
Background: Miltefosine, which is the first oral drug licensed for the treatment of leishmaniasis, was recently reported to be a promising lead compound for the synthesis of novel antischistosomal derivatives with potent activity in vivo against different developmental stages of Schistosoma mansoni. In this paper an in vitro study was carried out to investigate whether it has a biocidal activity against the aquatic stages of Schistosoma mansoni and its snail intermediate host, Biomphalaria alexandrina, thus being also a molluscicide. Additionally, to see whether miltefosine can have a broad spectrum antischistosomal activity, a similar in vitro study was carried out on the adult stage of Schistosoma haematobium, the second major human species, its larval stages and snail intermediate host, Bulinus truncutes. This was checked by scanning electron microscopy.

Results: Miltefosine proved to have in vitro ovicidal, schistolarvicidal and lethal activity on adult worms of both Schistosoma species and has considerable molluscicidal activity on their snail hosts. Scanning electron microscopy revealed several morphological changes on the different stages of the parasite and on the soft body of the snail, which further strengthens the current evidence of miltefosine's activity. This is the first report of mollusicidal activity of miltefosine and its in vitro schistosomicidal activity against S.haematobium.
\end{abstract}

Conclusions: This study highlights miltefosine not only as a potential promising lead compound for the synthesis of novel broad spectrum schistosomicidal derivatives, but also for molluscicidals.

\section{Background}

Miltefosine (hexadecylphosphocholine) is one of several alkyllysophospholipid derivatives collectively known as alkylphosphocholines that were originally developed as anticancer agents [1]. The biocidal action of miltefosine against Leishmania species was demonstrated in the mid 1980s [2,3] and since then, trials for its clinical evaluation have led to the licensing of miltefosine for the oral treatment of leishmaniasis in India, Colombia, and Germany [4-6]. Miltefosine is also active against a variety of protozoa, and more and more data have become available on its activity against other Kinetoplastidae (Trypanosoma cruzi and T. brucei) [7,8], Trichomonas

\footnotetext{
* Correspondence: mahaeissa19@yahoo.com

'Department of Medical Parasitology, Faculty of Medicine, Alexandria

University, Alexandria, Egypt

Full list of author information is available at the end of the article
}

vaginalis [9], Entamoeba histolytica [10] and several free living amoebas [11-13]. Apart from its antiprotozoal effect, various bioactivities of miltefosine have been reported; it has a broad spectrum antifungal activity [14], bactericidal activity against Streptococcus pneumoniae and other pathogenic Streptococci [15], and it is under investigation as a potential therapy against HIV infection [16]. The mechanism underlying broad range bioactivities and the target (s) is still unrevealed. Most recently, miltefosine was reported to have anthelminthic properties. In a study done in 2011 [17], miltefosine was found to have schistosomicidal activity and showed comparative advantage over PZQ in being effective against in vivo differential developmental stages of Schistosoma mansoni in the mouse model.

Schistosomiasis is one of the most prevalent diseases in the world, with about 200 million human beings 
infected in 74 countries. It is estimated that 20 million of them have serious forms of the disease or related disabilities, and that 200,000 people die from the disease every year [18]. Chemotherapeutic measures have been the mainstay in the control of this disease [19]. Since 1970, praziquantel (PZQ) has become the drug of choice against the three major human species of schistosomes, Schistosoma mansoni (Sambon), Schistosoma hematobium (Bilharz), and Schistosoma japonicum (Katsurada) $[20,21]$. It is a relatively safe, orally administered drug that leads to reduction of the prevalence of schistosomiasis [22]. Consequently a targeted as well as mass drug administration program presently relies heavily on this drug for the control of schistosome-induced morbidity.

With only one drug of choice for treatment and the possibility of development of parasite resistance [23-27], the present situation is dangerous. Therefore, there is a real need for discovery of a new drug.

Though chemotherapy is one of the most effective methods for the control of schistosomiasis [28], there is a basic need for more selective and efficient molluscicides for the control of the snail vectors. The control of snails is an important means in the combat against this disease. The presently available synthetic molluscicides tend to be generally biocidal affecting many other animals and/or plants in the snail habitat [29]. Therefore, there is a need to search for other molluscicides with strong but specific activity and less harmful to the environment. As miltefosine, was reported to be a promising lead compound for the synthesis of novel anti-schistosomal derivatives with potent activity against in vivo different developmental stages of S. mansoni [17], this study was carried out to investigate whether a similar activity can also exist against its aquatic stages and its snail intermediate host, Biomphalaria alexandrina, thus being a molluscicide. In addition, to elucidate whether miltefosine can have a broad spectrum antischistosomal activity, a similar in vitro study was carried out on the same stages, the intermediate host, and the adult worm of Schistosoma haematobium the second major human species. Miltefosine efficacy was evaluated on basis of in vitro bioactivity testing supported by scanning electron microscopy.

\section{Materials and methods \\ Drug}

Miltefosine (Milteforan ${ }^{\circledR}$ ) 2\% veterinary oral solution was kindly supplied by Dr. Paolo Bianciardi, Scientific Advisor,Virbac, Italy.

\section{Bioactivity testing In vitro schistosomicidal bioassay}

The schistosomicidal in vitro bioassay used here followed the main procedure previously described by [30] and [31]. Thus, the schistosome material Schistosoma mansoni (Sambon) and S. haematobium (Bilharz) was obtained from the Schistosome Biological Supply Centre (SBSC), Theodor Bilharz Research Institute (TBRI), Cairo, Egypt. Mature worms were obtained from hamsters (Mesocricetus auratus), percutaneously infected with 350-400 S. mansoni cercariae per hamster 6-7 weeks earlier, and with S. haematobium cercariae 11-12 weeks earlier. The worms were obtained by perfusion using citrated saline, and the recovered worms were washed from blood in small sieves ( $20 \mu \mathrm{m}$ mesh) by phosphate buffer. Worms were washed three times with the culture medium which is used for the assay under a sterilized laminar flow chamber. The culture medium used was RPMI $1640+$ l-glutamine $+20 \%$ fetal calf serum + antibiotics $(300 \mu \mathrm{g}$ streptomycin +300 IU penicillin $+160 \mu \mathrm{g}$ gentamycin per $\mathrm{ml}$ ). The bioassay was carried out using 24 wells tissue culture plates. A stock solution $5 \mathrm{mg} / \mathrm{ml}$ of the compound was prepared in DMSO immediately before being used. Three pairs of worms, males and females equally were used for each test well in $2 \mathrm{ml}$ medium and 2 replicats were set up for each species in each case. Exposure of worms to a standard concentration of $10 \mu \mathrm{g} / \mathrm{ml}$ of miltefosine (25 $\mathrm{uM}$ ) was made for 5 days at $37^{\circ} \mathrm{C} \pm 0.5^{\circ} \mathrm{C}$ in $5 \% \mathrm{CO} 2$ incubator. A pure medium and a medium containing $0.5 \%$ of DMSO (vehicle) were used as negative controls, while praziquantel at $10 \mu \mathrm{g} / \mathrm{ml}$ was used as a reference drug. Worms were examined for their viability using a stereomicroscope, and those not showing motility for one minute were considered dead. The mortality rate of worms was calculated after 5 days exposure. The compound was then retested (secondary screen) using the same technique by successive descending dilutions of the solution. The mortality of worms was determined in each case and the $\mathrm{LC}_{50}$ and $\mathrm{LC}_{90}$ were calculated. The statistical program SPSS version 7.5 was used for the calculation.

Larvicidal (ovicidal, miracidicidal and cercaricidal) activity Eggs, miracidia and cercariae of S. mansoni and S. haematobium were also obtained from SBSC. The eggs were extracted from the intestines of infected hamsters (Mescoricetus aurautus). Miracidia were obtained from cleaned eggs by hatching them in small amounts of dechlorinated tap water. The cercariae were procured from experimentally infected B. alexandrina and B.truncatus snails at $25^{\circ} \mathrm{C} \pm 2^{\circ} \mathrm{C}$. The eggs, miracidia and cercariae of both Schistosoma spp. were exposed to the $\mathrm{LC}_{50}$ of miltefosine determined below on snails for 30 min., $25 \mathrm{~min}$ and $20 \mathrm{~min}$ respectively. Sinking down of the miracidia and cercariae with detachment of the tail in the later case give indication of death of these organisms. 


\section{Molluscicidal tests}

The snail material used were Biomphalaria alexandrina (Ehrenberg) and Bulinus truncatus (Audouin), the vectors of S. mansoni and S. haematobium in Egypt respectively. They were also obtained from the colonies maintained in SBSC. Adult B. alexandrina and B. truncatus snails 4-6 $\mathrm{mm}$ in diameter and $2-3 \mathrm{~mm}$ shell height respectively were used for testing the molluscicidal activity of miltefosine. The snails were fed on boiled lettuce leaves, blue green algae and fish food.

The efficacy of miltefosine against the adult snails was primarily determined using the standard method of World Health Organization recommendations [29]. Thus one liter of solution with a concentration $20 \mathrm{ppm}$ was prepared and 10 snails were added. The snails were maintained in the solution for $24 \mathrm{~h}$ at $25^{\circ} \mathrm{C}+2^{\circ} \mathrm{C}$. After exposure, the snails were thoroughly washed and transferred to fresh water for another $24 \mathrm{~h}$ for recovery. Two replicas were carried out and two groups of snails were run in fresh dechlorinated water under the same experimental conditions as the negative control. The currently conventional molluscicide (Niclosamide) was used similarly as positive control. At the end of recovery period, the snails were examined for viability, and the dead snails were counted and recorded to calculate the mortality rate. Miltefosine was then retested by the same method using descending concentrations for $\mathrm{LC}_{50}$ and $\mathrm{LC}_{90}$ determination. The statistical program SPSS package version 7.5 was used for calculation.

\section{Scanning electron microscopy study}

Eggs, miracidia, cercariae as well as adult worms of Schistosoma mansoni, and the soft body of its snail host, B. alexandrina, exposed to miltefosine, and non exposed samples that served as controls were fixed in a $10 \%$ glutaraldehyde and processed for examination by SEM [32].

\section{Ethical approval}

All animal studies presented here have been approved by the local government based on national regulations for animal experimentation.

\section{Results \& discussion}

In vitro schistosomicidal activity

Miltefosine showed $100 \%$ mortality of worms at $10 \mu \mathrm{g} / \mathrm{ml}$ after 5 days exposure. It was slightly more effective on adult worms of $S$. haematobium than on S. mansoni with $\mathrm{LC}_{50}$ of $5.1 \mu \mathrm{g} / \mathrm{ml}$ and $5.8 \mu \mathrm{g} / \mathrm{ml}$ for the two spp. respectively. However this effect is still much less than that of the reference drug (PZQ) which gave $\mathrm{LC}_{50}=0.2 \mu \mathrm{g} / \mathrm{ml}$ after 5 days under the same condition (Table 1 ). This difference in susceptibility of the two species to miltefosine may be explained by one of the several hypotheses raised by Eissa et al., 2011 [17] for the possible mechanisms of action of miltefosine in schistosomiasis. They postulated
Table 1 In vitro schistosomicidal activity of miltefosine on Schistosoma mansoni and Schistosoma haematobium adult worms (after 5 days exposure).

\begin{tabular}{lllll}
\hline Schistosoma spp. & \multicolumn{2}{l}{ Miltefosine } & \multicolumn{2}{l}{ Praziquantel } \\
\cline { 2 - 5 } & $\begin{array}{l}\mathrm{LC}_{\mathbf{5 0}} \\
\boldsymbol{\mu g} / \mathbf{m l}\end{array}$ & $\begin{array}{l}\mathrm{LC}_{\mathbf{9 0}} \\
\boldsymbol{\mu g} / \mathrm{ml}\end{array}$ & $\begin{array}{l}\mathrm{LC}_{\mathbf{5 0}} \\
\boldsymbol{\mu g} / \mathbf{m l}\end{array}$ & $\begin{array}{l}\mathrm{LC}_{\mathbf{9 0}} \\
\boldsymbol{\mu g} / \mathbf{m l}\end{array}$ \\
\hline S.mansoni & 5.8 & 8.2 & 0.2 & 0.3 \\
\hline S.haematobium & 5.1 & 7.1 & 0.2 & 0.3 \\
\hline
\end{tabular}

that miltefosine may act through acetylcholine esterase inhibition due to the presence of phosphocholine moiety in its structure, a mechanism of action which is well known for the potent schistosomicidal drug, metrifonate, which was widely used against S.haematobium in the 1990s, and then withdrawn from the market because of medical, operational and economic criteria [33,34]. It is well known that $S$. mansoni and S. haematobium differ in their sensitivity to this therapeutic anticholinesterase, metrifonte, that exhibits activity against $S$. haematobium singly [35,36]. As Miltefosine was postulated to have anticholine esterase activity, we hypothesize that this may act synergistically with other postulated mechanisms raised for miltefosine by Eissa et al., 2011 [17], thus explaining the slight difference of susceptibility of the two species to miltefosine. However, further research is needed to provide a better understanding of the contribution of this factor in determining the different susceptibility of the two spp. to miltefosine.

In the present study, SEM of adult male S.mansoni worm exposed in vitro to miltefosine at a concentration of $10 \mathrm{ug} / \mathrm{ml}(25 \mathrm{uM})$ showed distortion of the tubercles on the dorsal tegumental surface (Figure 1A). There was erosion of the tegumental surface (Figure 1B, C) with appearance of subtegumental tissue (Figure 1D). There was also constriction at the posterior end of the worm (Figure 1E). The normal dorsal tegumental tubercles from the negative controls (pure medium controls) are shown in (Figure 1F). SEM of worms from DMSO controls appeared similar to those from pure medium controls. SEM of the tegument of adult $S$. mansoni worms has been described since the seventies $[37,38]$. The present results show that miltefosine caused disintegration of the tubercles on the dorsal tegumental surface with its sloughing and erosion leading to exposure of the subtegumental tissue. These findings are similar but more pronounced than the changes observed by Eissa et al., 2011 [17] in their in vivo study. These results are also in accordance with tegumental alteration induced by mefloquine on adult S. mansoni in both in vitro and in vivo studies [39].

\section{Ovicidal, miracidicidal and cercaricidal activities}

Miltefosine proved to have clear schistolarvicidal effect on S. mansoni and S. haematobium. Thus eggs did not 

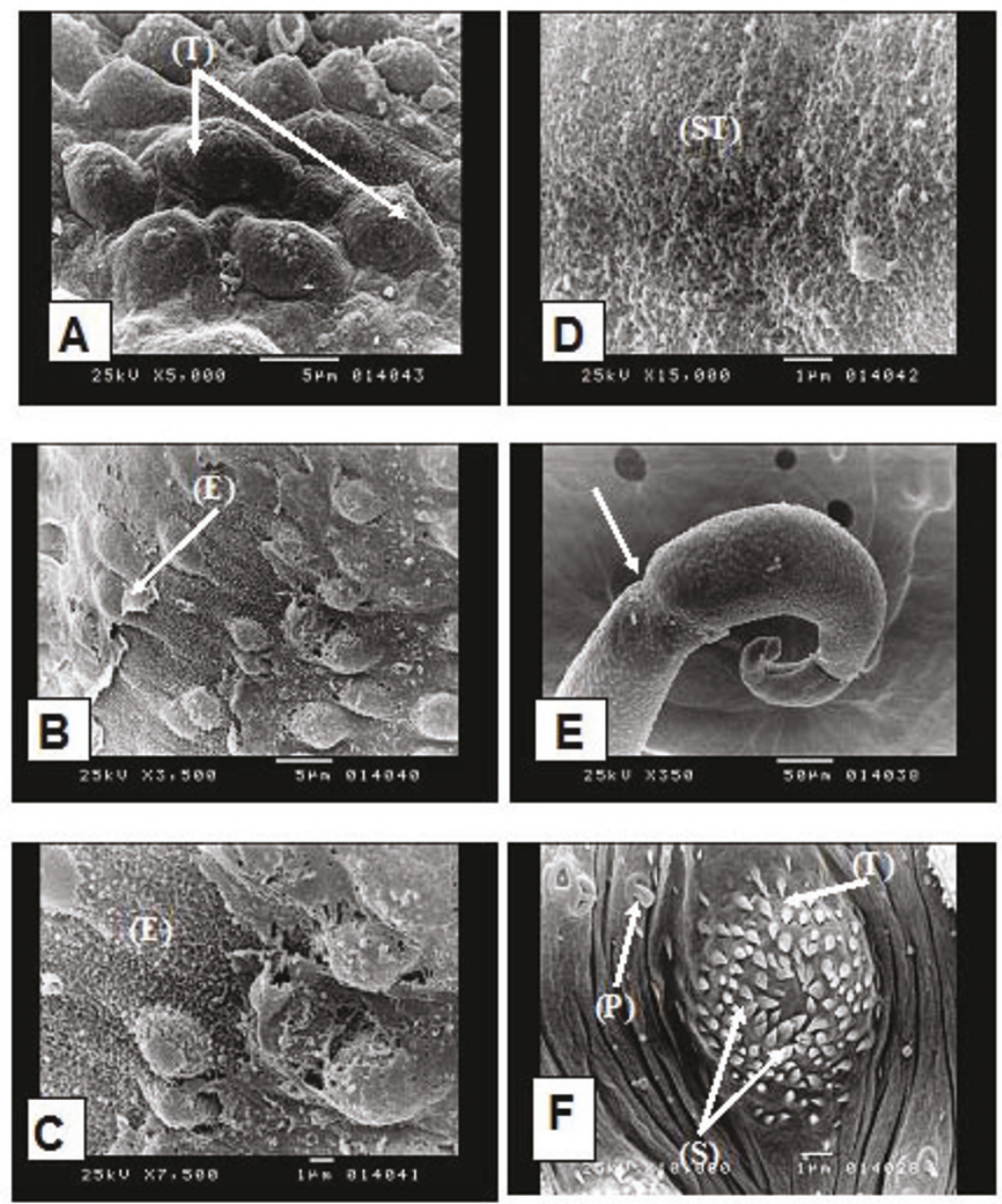

Figure 1 Scanning electron microscopy (SEM) of adult Schistosoma mansoni: in vitro exposed adult to miltefosine showing: (A) distorted dorsal tegumental tubercles on the dorsal surface $(T)(\times 5000)$, (B) erosion of the tegumental surface $(E)(\times 3500)$, (C) higher magnification of (B) $(\times 7500)$, (D) appearance of subtegumental tissue (ST) $(\times 15000)$, (E) constriction at the posterior end of the worm $(\rightarrow)(\times 350)$. Unexposed adult showing: $(\mathbf{F})$ dorsal tegumental tubercle $(T)$ of a normal male worm showing its spines $(S)$ and papillae $(P)(\times 10000)$

hatch at a concentration equal to $\mathrm{LC}_{50}$ of the drug on the corresponding snail vector (Table 2). However, the drug was more effective on $S$. haematobium than on $S$. mansoni. The compound leads to reduction in the movement of the miracidia and the sinking down of the cercariae to the bottom of the container with detachment of the tails. This was followed by the death of both organisms. Thus, this study showed also that miltefosine not only possesses the potential of being broad spectrum antischistosomal compound but also has schistolarvicidal activity against aquatic stages of both $S$. mansoni and S. haematobium. The biocidal activity of miltefosine was demonstrated against $S$. mansoni and $S$. haematobium eggs, leading to prevention of hatching when eggs were exposed to the mollusicicdal $\mathrm{LC}_{50}$, half and quarter this compound concentration. SEM study of $S$. mansoni egg showed that normal egg has microspicules like chitinous minute projections densely distributed all over the surface (Figure 2A\& B). On the other hand, eggs exposed to miltefosine at a concentration of $3.75 \mathrm{ppm}$ showed patchy loss of these projections (Figure 2C, D). The remaining ones became oedematous and swollen (Figure 2E). Previous literature showed that the egg shell of $S$. mansoni consists of dense material with multiple microspicules on its outer surface and pores through its thickness [40]. Within the shell is the live miracidium, which releases enzymes and antigens [41]. The present SEM of S. mansoni eggs after exposure to miltefosine showed destruction and patchy loss of the microspicules of the egg shell, which may 
Table 2 Ovicidal and schistolarvicidal activity of miltefosine on Schistosoma mansoni and Schistosoma haematobium

\begin{tabular}{|c|c|c|c|c|}
\hline \multirow[t]{2}{*}{$\begin{array}{l}\text { Schistosoma } \\
\text { spp. }\end{array}$} & \multirow[t]{2}{*}{$\begin{array}{l}\text { Concentration of } \\
\text { Miltefosine } \\
\text { Solution }(\mu \mathrm{g} / \mathrm{m} \mathrm{I}) \\
\text { Molluscidal LC } 50\end{array}$} & $\begin{array}{l}\text { Ovicicdal } \\
\text { Effect }\end{array}$ & $\begin{array}{l}\text { Miracidicidal } \\
\text { Effect }\end{array}$ & $\begin{array}{l}\text { Cercaricidal } \\
\text { Effect }\end{array}$ \\
\hline & & $\begin{array}{l}100 \% \text { mortality after } \\
\text { (minutes) }\end{array}$ & $\begin{array}{l}100 \% \text { mortality after } \\
\text { (minutes) }\end{array}$ & $\begin{array}{l}100 \% \text { mortality after } \\
\text { (minutes) }\end{array}$ \\
\hline \multirow[t]{4}{*}{ S. mansoni } & 7.5 & 5 & 10 & 20 \\
\hline & $3.75(1 / 2)$ & 10 & 15 & 30 \\
\hline & $1.85(1 / 4)$ & 20 & 20 & 40 \\
\hline & $0.925(1 / 8)$ & 30 & 30 & 50 \\
\hline \multirow[t]{4}{*}{ S. haematobium } & 2.6 & 10 & 20 & 30 \\
\hline & $1.3(1 / 2)$ & 20 & 30 & 45 \\
\hline & $0.65(1 / 4)$ & 0 & 40 & 55 \\
\hline & $0.33(1 / 8)$ & 0 & 60 & 60 \\
\hline
\end{tabular}
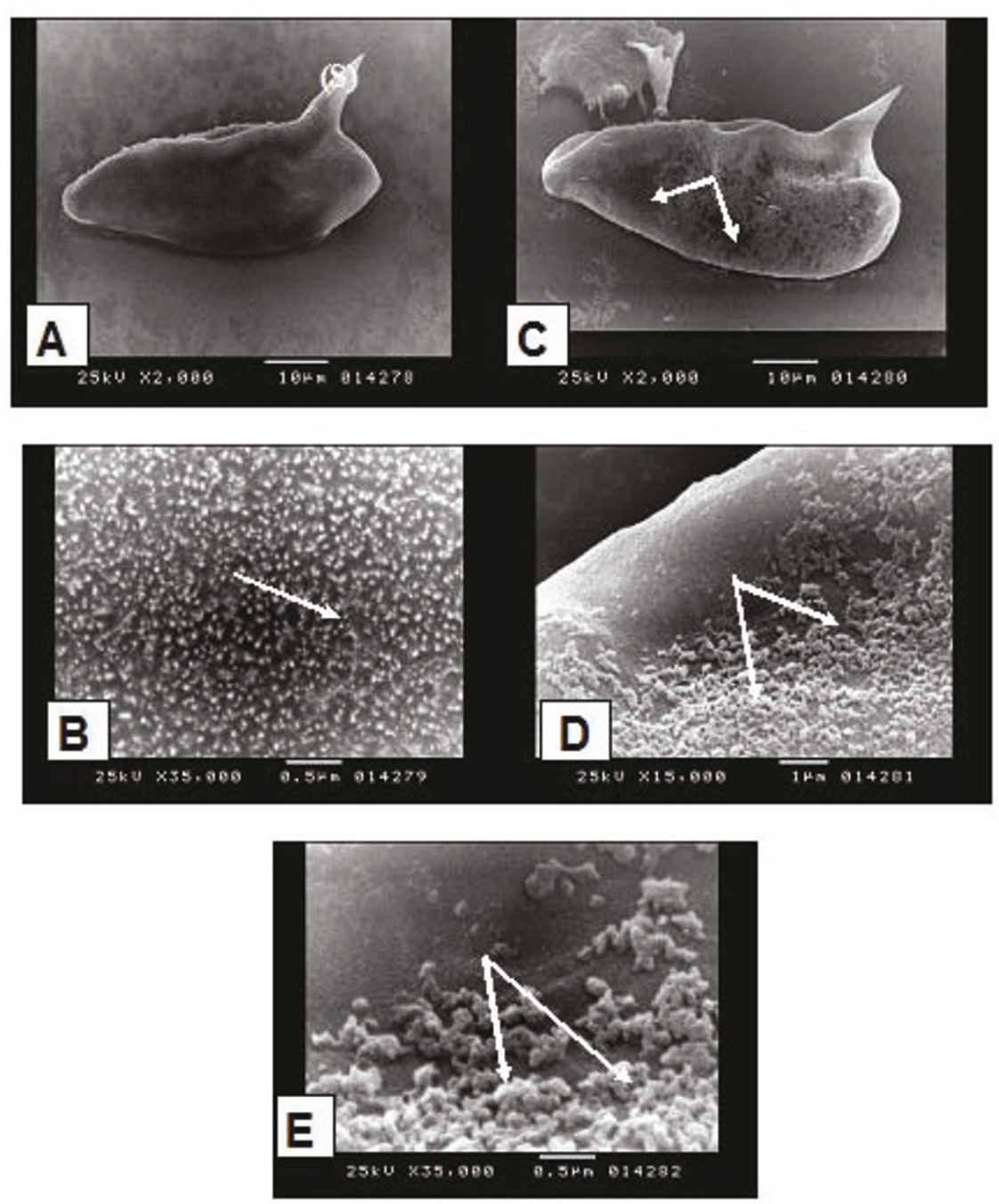

Figure 2 Scanning electron microscopy (SEM) of Schistosoma mansoni eggs: unexposed eggs showing: (A) oval egg with lateral spine (S) $(\times 2000)$, (B) the surface of the egg showed microspicules like chitinous projections $(\rightarrow)(\times 35000)$. Exposed eggs to miltefosine showing: (C) patchy loss of the microspicules like chitinous projections $(\rightarrow)(\times 2000)$, (D) higher magnification of (C) ( $\times 15000)$, (E) swollen and oedematous chitinous projections $(\rightarrow)(\times 35000)$. 
indicates that miltefosine can diffuse easily and find its way inside the eggs. This, in addition to the porous shell of the egg that allows the drug to reach the metabolically active miracidium, where it may interfere with its antigenic substances and enzymes leading to the loss of their capability of hatching. Hatching of Schistosoma eggs is the culmulation of multiple biological processes and severe damage to several of these processes may be needed to be manifest as a decrease in the release of miracidia [40]. Further documenting this hypothesis is the observation of small granuloma size in the liver of experimentally infected mice with $S$. mansoni after treatment with miltefosine [17], that was explained by the authors due to the effect on eggs in situ by miltefosine which is known to accumulate in the liver after oral administration, thus diminishing the capacity of the eggs to induce delayed type hypersensitivity granulomas in the liver. Impairment of the antigenic products is clearly important to the host as morbid complications of schistosomiasis are largely related to the granulomatous and fibrotic responses to egg deposition in the tissues [42].

The present study showed also that miltefosine has biocidal activity against miracidia and cercariae of both Schistosoma species. Miltefosine leads to the reduction in movement of miracidia and sinking of the cercariae to the bottom of the container, this was followed by the death of both organisms. SEM studies showed that the normal unexposed miracidium of $S$. mansoni is covered with cilia (Figure 3A, B). The apical papillae showed the characteristic honey comb pattern of its terebratorium (Figure $3 \mathrm{C}$ ). where as, the miracidium exposed to miltefosine at a concentration of $3.75 \mathrm{ppm}$ showed distinct loss of cilia from its surface (Figure 3D) and the protruded apical papillae showed swollen oedematous corrugated areas (Figure 3E, F).

An SEM study of miracidia has been previously carried out by [43] and [44]. SEM of S.mansoni miracidium exposed to miltefosine showed loss of cilia from its surface, and the protruded apical papilla showed swollen oedematous corrugated areas. As a result the miracidium loses its ability to swim in water searching for its snail host. It may also lose its capability to penetrate the snails, because of the changes in the apical papilla [43].

In the present study, SEM of unexposed cercariae showed that the cercarial glycocalyx envelops the whole organism (Figure 4A). The most anterior part of the head is provided with spiny tegumental folds (Figure $4 \mathrm{~B})$. At the body region the surface was irregular showing invagination and infolding of the tegument forming frequent tubular profiles (Figure 4B). The body is covered with numerous spines which are posteriorly directed and are covered with a glycocalyx that obscured these spines (Figure 4C). The cercarial tail and its furculae are covered by the glycocalyx similar to that seen on the body but the tips of the spines were often visible, larger and sharper than those of the body (Figure 4D). Cercariae exposed to miltefosine at a concentration of 3.75 ppm showed partial detachment of the body from the tail (Figure 4E), whereas in other cercariae, the body appeared completely separated from the tail (Figure 4F). There was marked loss of the glycocalyx, and thining of the tegument leading to external protrusion or surface blebbing (Figure 4E, G, inset), with focal loss of spines from the tegument (Figure $4 \mathrm{H}$ ). SEM of $S$. mansoni cercariae has been described in a number of studies $[45,46]$. In the present study, S. mansoni cercariae exposed to miltefosine at concentration $3.75 \mathrm{ppm}$ showed different morphological changes. Gross changes were observed, including loss of tails in about $80 \%$ of cercariae. These observations were consistent with the report of [47] and [48] which showed that hinokitiol $(\beta$ thujaplicin), a compound for potential skin application against cercarial penetration leads to loss of cercarial tail in about $50 \%$ of cercariae thus affecting cercarial movement and swimming activity. SEM also revealed loss of glycocalyx resulting in the thinning of the tegument causing external protrusion or surface blebbing with focal loss of spines. These changes are similar to the changes observed on the cercariae of S.mansoni exposed to hinokitiol by [48]. Those authors suggested that the structural changes may account for the inability of hinokitiol-treated cercariae to infect the host. Moreover, the surface blebbing is considered as an indicator for stress and has been observed in previous SEM studies evaluating anti-schistosomal drugs [49,39].

\section{Molluscicidal activity}

The results of this study showed that miltefosine has a considerable molluscicidal effect on both $B$. alexandrina and $B$. truncatus snails. B. truncatus is considrably more susceptible than $B$. alexandrina, $\mathrm{LC}_{50}$ for Bulinus was $2.6 \mathrm{ppm}$ vs. $7.5 \mathrm{ppm}$ for Biomphalaria after $24 \mathrm{~h}$ at $26^{\circ}$ C. This molluscicidal effect is still much lower than that of niclosamide which is the conventional synthetic molluscicide commonly used at present, $\mathrm{LC}_{50}$ of niclosamide is $0.2 \mathrm{ppm}$ under the same condition (Table 3 ). SEM of the unexposed soft body of $B$. alexandrina snail showed that the ventral surface of the foot is covered with cilia (Figure 5A, B) whereas, the tegumental surface of the mantle covering the visceral mass is almost smooth (Figure 5C). B. alexandrina snails exposed to miltefosine at concentration of $5 \mathrm{ppm}$ showed extensive damage of the cilia at the foot (Figure 5D). There was also extensive damage of the tentacles with erosion and exfoliation especially at its apical part with appearance of the subtegumental tissue (Figure 5E). The mantle showed erosion, peeling and exfoliation of its tegumental surface that resulted in the exposure of the 

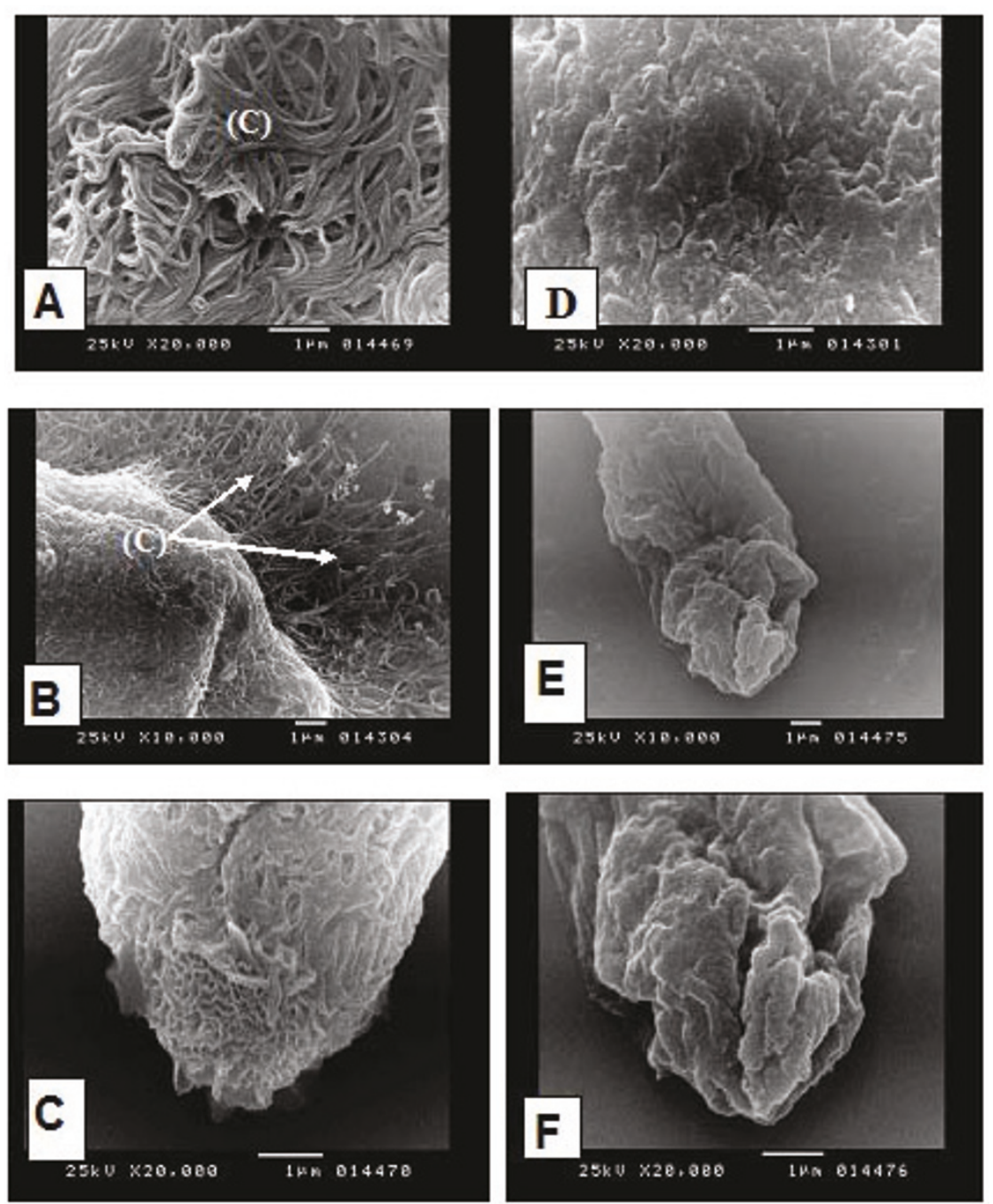

Figure 3 Scanning electron microscopy (SEM) of S. mansoni miracidia, unexposed miracidia showing: (A) cilia (C) covering the surface of the miracidium $(\rightarrow)(\times$ 20000), (B) cilia (C) covering the miracidium $(\rightarrow)$ and extending from its lateral side $(\times 10000)$, (C) the apical papillae of the miracidium with its characteristic honey comb pattern of its terebratoria $(\rightarrow)(\times 20000)$. Miracidium exposed to miltefosine showing: (D) loss of cilia from the surface of miracidium ( $\times 20000)$, (E) protruded apical papillae with swollen oedematous corregated areas $(\times 10000)$, (F) higher magnification of $(E)(\times 20000)$.

subtegumental tissue (Figure 5F). These changes are reminiscent of the morphological changes observed in scanning electron microscopy of tumor cells treated with miltefosine [50] and in adult Schistosoma mansoni after experimental in vivo treatment with miltefosine [17].

A review of the literature showed that a number of studies have been carried out on the effect of several compounds and plant extracts on miracidia and cercariae as well as medically important snails with various degrees of success [51-54].

Although, the results of this study demonstrated the molluscicidal activity of miltefosine, its broad biocide activity may makes it unsuitable for snail control.
Therefore, this study draws attention to miltefosine as a promising lead compound for the synthesis of more potent and selective molluscicidal derivatives.

\section{Conclusions}

This study showed that miltefosine has a schistolarvicidal activity on the different aquatic stages of S.mansoni and S.haematobium, and a lethal in vitro effect on adult worm of both species. In addition, considerable molluscicidal activity was also demonstrated against their snail hosts. These biocidal activities were supported by SEM studies which further strengthen current evidence of miltefosine's activity. To the best of our knowledge, this is the first report of mollusicidal activity of miltefosine 

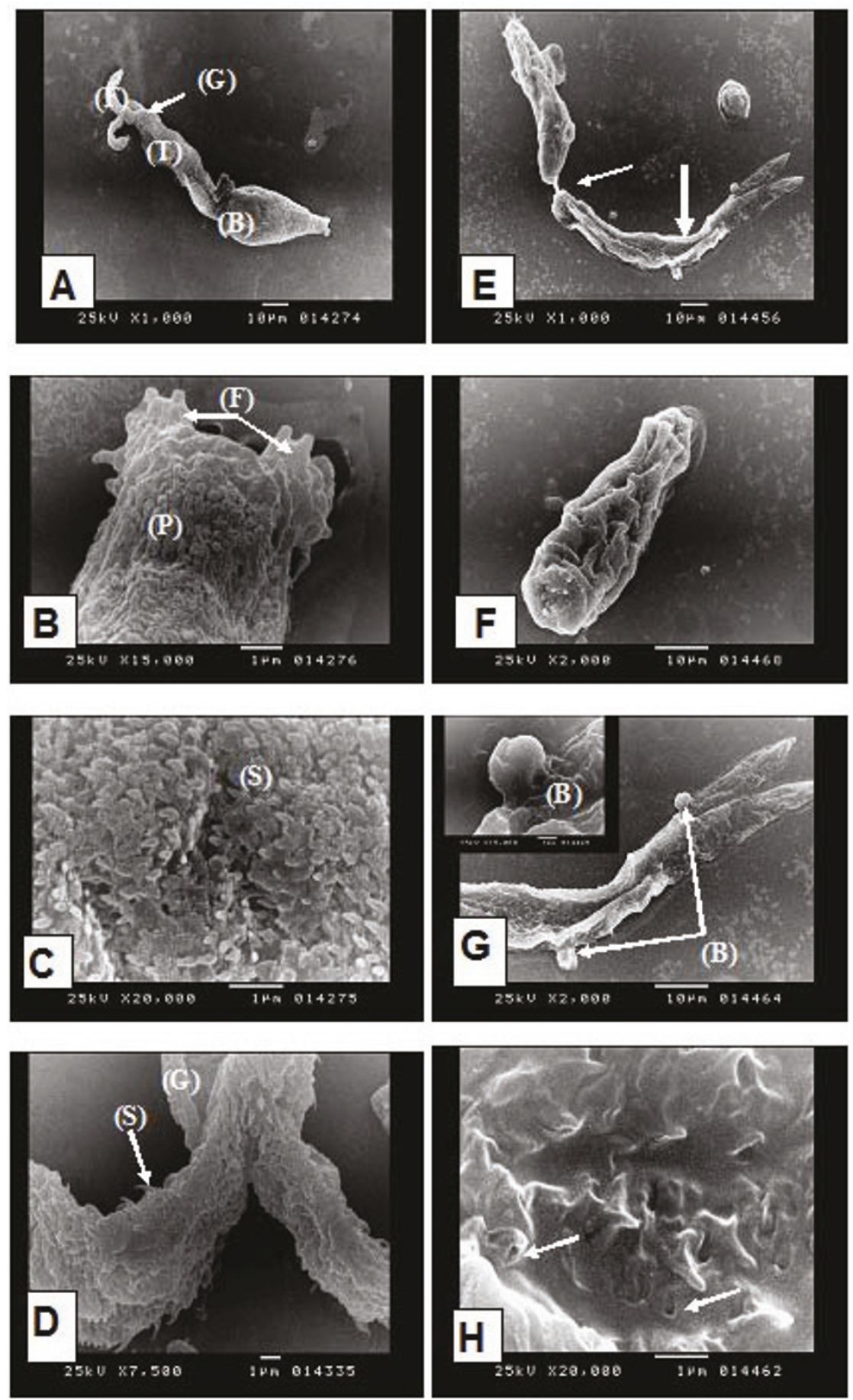

Figure 4 Scanning electron microscopy (SEM) of Schistosoma mansoni cercariae: normal cercaria showing: (A) cercarial body (B) and tail (T) with its two furculae $(F)$, covered with glycocalyx $(G)(\times 1000)$, (B) tegumental folds $(F)$ at the most anterior part of the head and evident tubular profiles (P) (X 15000), (C) numerous spines (S) covering the body region which are directed posteriorly and are covered with a glycocalyx that obscured these spines ( $\times$ 20000), (D) the cercarial tail with its two furculae covered with glycocalyx (G) identical to that seen on the body but the tips of the spines $(S)$ were often visible, larger and sharper than those of the body $(\times 7500)$. Cercaria exposed to miltefosine showing: $(E)$ partial detachment of the body from the tail $(\rightarrow)$ with marked loss of the glycocalyx, thining of the tegument $(\rightarrow)$ and surface blebbing $(\times$ 1000), (F) separated cercarial body ( $\times 2000)$, (G) surface blebbing of the tegument $(B)(\times 2000$, inset $\times 15000)$. (H) focal loss of tegumental spines $(\rightarrow)(\times 20000)$. 
Table 3 Molluscicidal activity of miltefosine on Biomphalaria alexandrina and Bulinus truncatus snails after 24 hours at $25^{\circ} \mathrm{C}+2^{\circ} \mathrm{C}$

\begin{tabular}{lllll}
\hline Snail species & Miltefosine & \multicolumn{2}{l}{ Niclosamide } \\
& $\begin{array}{l}\mathbf{L C}_{\mathbf{5 0}} \\
(\mathbf{p p m})\end{array}$ & $\begin{array}{l}\mathbf{L C}_{\mathbf{9 0}} \\
(\mathbf{p p m})\end{array}$ & $\begin{array}{l}\mathbf{L C}_{\mathbf{5 0}} \\
(\mathbf{p p m})\end{array}$ & $\begin{array}{l}\mathbf{L C}_{\mathbf{9 0}} \\
(\mathbf{p p m})\end{array}$ \\
\hline B. alexandrina & 7.5 & 9.9 & 0.2 & 0.6 \\
B. truncates & 2.6 & 4.2 & 0.2 & 0.6 \\
\hline
\end{tabular}

and its in vitro schistosomicidal activity against S.haematobium. Thus, this study highlights miltefosine not only as a potential promising lead compound for the synthesis of novel broad spectrum schistosomicidal derivatives but also for molluscicidals.

\section{Acknowledgements}

We are grateful to Dr. Paolo Bianciardi, Scientific Advisor, Virbac, Italy, for providing miltefosine used in this study.

\section{Author details}

'Department of Medical Parasitology, Faculty of Medicine, Alexandria University, Alexandria, Egypt. ${ }^{2}$ Department of Medical Malacology, Theodor Bilharz Research Institute, Imbaba, Cairo, Egypt.

\section{Authors' contributions}

MME: conceived and designed the research, performed the experiment and SEM study, literature search, wrote and revised the manuscript. SEB: designed the research, performed the experiment and SEM study, literature search, wrote and revised the manuscript. MT: performed the experiment wrote and revised the manuscript.

All authors approved the final version of the manuscript.

\section{Competing interests}

The authors declare that they have no competing interests.
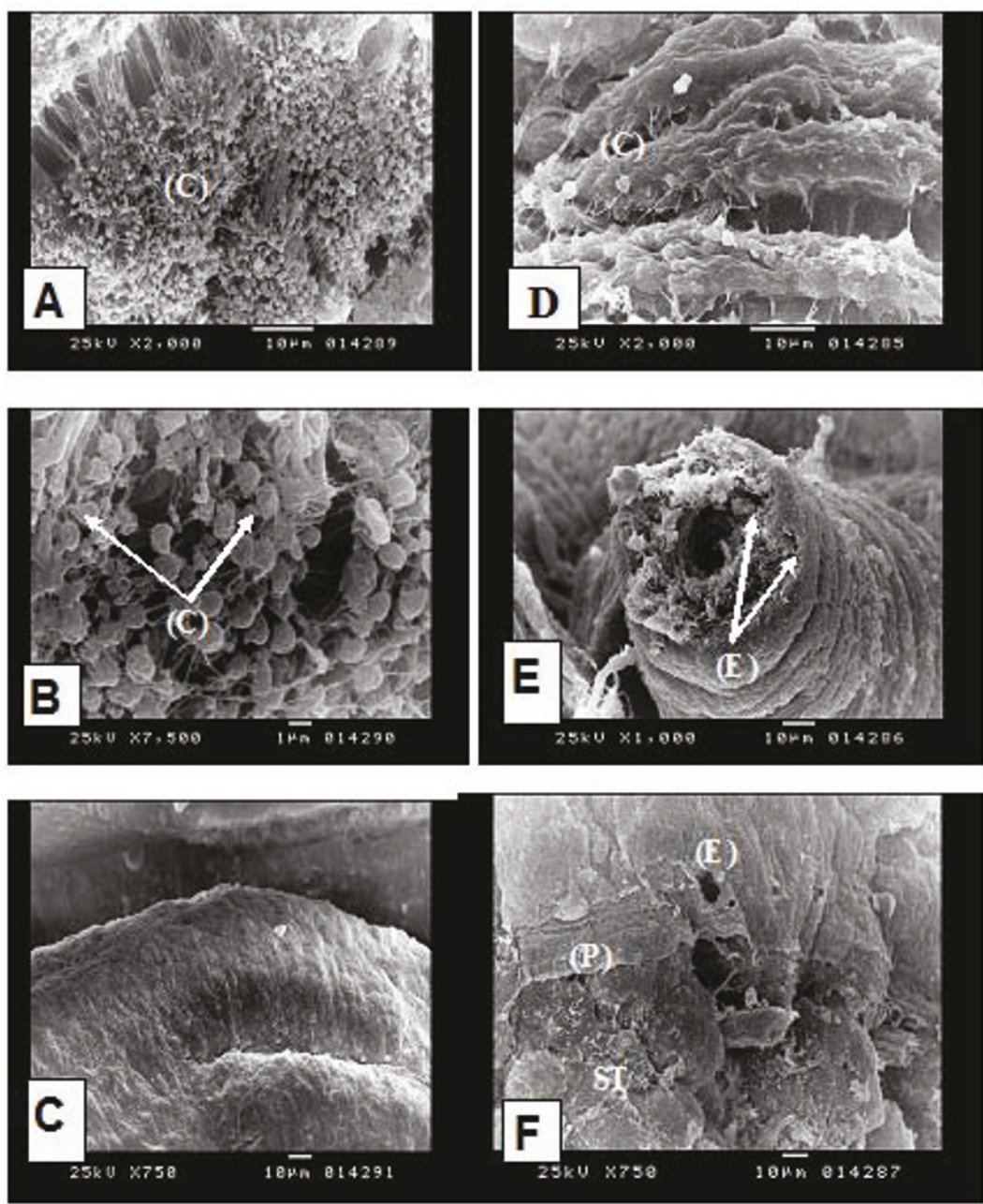

Figure 5 Scanning electron microscopy (SEM) of Biomphalaria alexandrina snail (soft part): normal snail showing: (A) densly attached numerous cilia (C) at the ventral surface of the foot region ( $\times 2000)$, (B) higher magnification of (A) showing cilia (C) $(\times 7500)$, (C) smooth tegumental surface of the mantle/visceral mass $(\times 750)$. Snail exposed to miltefosine showing: (D) extensive damage of the cilia at the foot region (C) ( $\times 2000)$, $(E)$ extensive damage of the tentacles with erosion $(E)$ and exfoliation especially at its apical part with appearance of the subtegumental tissue $(\times 1000)$, $(F)$ the mantle showed erosion $(E)$, peeling $(P)$ and exfoliation of its tegumental surface that results in exposure of the subtegumental tissue (ST) $(\times 750)$. 
Received: 28 March 2011 Accepted: 11 May 2011

Published: 11 May 2011

\section{References}

1. Brachwitz H, Vollgraf C: Analogs of alkyllysophospholipids: chemistry. Effects on the molecular level and their consequences for normal and malignant cells. Pharmacol Ther 1995, 66:39-82.

2. Berman JD: Development of miltefosine for the leishmaniases. Mini Rev Med Chem 2006, 6:145-151.

3. Croft SL, Engel J: Miltefosine-discovery of the antileishmanial activity of phospholipid derivatives. Trans R Soc Trop Med Hyg 2006, 100:S4-S8.

4. Perez-Victoria FJ, Sanchez-Canete MP, Seifert K, Croft SL, Sundarr S, Castanys S, Gamarro F: Mechanisms of experimental resistance of Leishmania to miltefosine: implications for clinical use. Drug Resist Updates 2006, 9:26-39.

5. Sindermann H, Engel J: Development of miltefosine as an oral treatment for leishmaniasis. Trans R Soc Trop Med Hyg 2006, 100(Suppl 1):S17-S20.

6. Soto J, Berman J: Treatment of New World cutaneous leishmaniasis with miltefosine. Trans R Soc Trop Med Hyg 2006, 100:S34-S40.

7. Croft SL, Snowdon D, Yardley V: The activites of four anticancer alkyllysophospholipids against Leishmania donovani, Trypanosoma cruzi and Trypanosoma brucei. J Antimicrob Chemother 1996, 38:1041-1047.

8. Saraiva VB, Gibaldi D, Previato JD, Mendonça-previato L, Bozza MT, Freirede-Lima CG, Heise N: Proinflamatory and cytotoxic effects of hexadecylphosphocholine (miltefosine) against drug-resistant strains of Trypanosoma cruzi. Antimicrob Agents Chemother 2002, 46:3472-3477.

9. Blaha $C$, Duchêne $M$, Aspöck $H$, Walochnik J: In vitro activity of hexadecylphosphocholine (miltefosine) against metronidazole-resistant and- susceptible strains of Trichomonas vaginalis. J Antimicrob Chemother 2006, 57:273-278.

10. Seifert $K$, Duchenne $M$, Wernsdorfer $W H$, Kollaritsch $H$, Scheiner $O$, Wiedermann G, Hottokowitz T, Eibl H: Effects of miltefosine and other alkylphosphocholines on human intestinal parasite Entamoeba histolytica. Antimicrob Agents Chemother 2001, 45:1505-1510.

11. Walochnik J, Duchene M, Seifert K, Obwaller A, Hottkowitz T Wiedermann G, Eibl H, Aspock H: Cytotoxic activites of alkylphosphocholines against clinical isolates of Acanthamoeba spp. Antimicrob Agents Chemother 2002, 44:695-701.

12. Schuster FL, Guglielmo BJ, Visvesvara GS: In- vitro activity of miltefosine and voriconazole on clinical isolates of free-living amehas: Balamuthia mandrillaris, Acanthamoeba spp., and Naegleria fowleri. J Eukaryot Microbial 2006, 53:121-126.

13. Walochnik J, Obwaller A, Gruber F, Mildner M, Tschachler E, Suchomel M, Duchene M, Auer H: Anti-Acanthamoeba efficacy \& toxicity of miltefosine in an organotypic skin equivalent. J Antimicrob Chemother 2009, 64:539-545.

14. Widmer F, Wright LC, Obando D, Handke R, Ganendren R, Ellis DH, Sorrell TC: Hexadecylphosphocholine (miltefosine) has broad-spectrum fungicidal activity and is efficacious in a mouse model of cryptococcosis. Antimicrob Agents Chemother 2006, 50(2):414-412.

15. Llull D, Rivas L, Garcia E: In vitro bactericidal activity of the antiprotozoal drug miltefosine against Streptococcus pneumoniae and other pathogenic Streptococci. Antimicrob Agents Chemother 2007, 51:1844-1848

16. Chugh P, Bradel-Tretheway B, Monteiro-Filho CM, Vicente P, Sanjay M, Stephen D, Baek k: AKT inhibitors as an HIV-1 infected macrophagespecific anti-viral therapy. Retrovirology 2008, 5:11

17. Eissa MM, EL-Azzouni MZ, Amer El, Baddour NM: Miltefosine, a promising novel agent for Schistosomiasis mansoni. Int J Parasitol 2011, 41:235-242

18. World Health Organization (WHO): Prevenion and control of schistosomiasis and soil transmitted helminthiasis. Report of a WHO Expert Committee, Geneva. WHO Technical Report Series; 2002:912:1-57.

19. Fenwick A, Webster JP: Schistosomiasis: challange for control, treatment and drug resistance. Curr Opin Infect Dis 2006, 19:577-582.

20. Gonnert R, Andrew P: Praziquantel, a new board-spectrum antischistosomal agent. Z Parasitenkd 1977, 52:129-150.

21. Doenhoff MJ, Pica-Mattoccia L: Praziquantel for the treatment of schistosomiasis: its use for control in areas with endemic disease and prospects for drug resistance. Expert Rev Anti infe 2006, 4:199-210.

22. Southgate VR, Rollinson D, Tchuen Tchuente A, Hagan P: Towards control of schistosomiasis in sub-Saharan Africa. J Helminthol 2005, 79:181-185.
23. Ismail M, Botros $S$, Metwally A, William S, Farghally A, Tao LF, Day TA, Bennett JL: Resistance to praziquantel: direct evidence from Schistosoma mansoni isolated from Egyptian villagers. Am J Trop Med Hyg 1999, 60:932-935.

24. Doenhoff M, Kusel JR, Coles GC, Cioli D: Resistance of Schistosoma mansoni to praziquantel: Is there a problem ? Trans $R$ Soc Trop Med Parasitol 2002, 96:465-469.

25. Lawn SD, Lucas SB, Chiodini PL: Case report: Schistosoma mansoni infection: failure of standard treatment with praziquantel in a returned traveler. Trans R Soc Trop Med Hyg 2003, 97:100-101.

26. Alonso D, Munoz J, Gascòn J, Valls ME, Corachan M: Failure of standard treatment with praziquantel in two returned travelers with Schistosoma haematobium infection. Am J Trop Med Hyg 2006, 74:342-344.

27. Botros SS, Bennett J: Praziquantel resistance. Expert Opin Drug Discov 2007, 2:S35-S40

28. World Health Organization (WHO): In Epidemiology and control of schistosomiasis. Volume 643. WHO Technical Report Series; 1980.

29. World Health Organization (WHO): Molluscicide screening and Evaluation. Bull World Health Organ 1965, 33:567-581.

30. Yousif F, Hifnawy MS, Soliman G, Boulos L, Labib TH, Mahmoud S, Ramzy F, Yousif M, Hassan I, Mahmoud K, El-Hallouty SM, EL-Gendy M, Gohar L, ELManawaty M, EL-Menshawi BS: Large-scale in vitro screening of Egyptian native and cultivate plants for schistosomicidal activity. Pharma Biol 2007, 45:501-510.

31. Ramirez B, Bickle Q, Yousif F, Mouries MA, Nwaka S: Schistosoma Challenge in compound screening. Expert opinion Drug Discovery 2007, 2:1-9.

32. Shaw MK, Erasmus DA: Schistosoma mansoni : structural damage and tegumental repair after in vivo treatment with praziquantel. Parasitology 1987, 94:243-254.

33. Feldmeier $\mathrm{H}$, Chitsulo L: Therapeutic and operational profiles of metrifonate and praziquantel in Schistosoma haematobium infection. Arzneimittelforschung 1999, 49:557-565.

34. Danso-Appiah A, Gamer P, Olliaro PL, Utzinger J: Treatment of urinary schistosomiasis: methodological issues and research needs identified through a cochrane systematic review. Parasitology 2009, 136:1837-1849.

35. Bentley GN, Jones AK, Agnew A: Mapping and sequencing of acetylcholinestrase genes from the platyhelmimth blood fluke Schistosoma. Gene 2003, 18:103-112.

36. Utzinger J, Keiser J, Shuhua X, Tanner M, Singer BH: Combination chemotherapy of schistosomiasis in laboratory studies and clinical trials. Antimicrob Agents Chemother 2003, 47:1487-1495.

37. Miller FH, Tulloch GS, Kuntz RE: Scanning electron microscopy of integumental surface of Schistosoma manosni. J Parasitol 1972, 58(6):93-698.

38. Hockley DJ: Ultrastructure of the tegument of Schistosoma. Adv Parasi 1973, 11:232-305.

39. Manneck T, Haggenmuller YO, Keiser J: Morphological effects and tegumental alterations induced by mefloquine on schistosomula and adult flukes of Schistosoma mansoni. Parasitolog 2010, 137:85-98.

40. Kazura JW, De Brito P, Rabbege J, Alkawa M: Role of granulocyte oxygen products in damage of Schistosoma mansoni eggs in vitro. $J$ Clin Invest 1985, 75:1297-1307.

41. Seed JL, Bennett JL: Schistosoma mansoni phenol oxidase's role in egg shell formation. Exp Parasitol 1980, 49:430-441

42. Warren KS: The immunopathogenesis of schistosomiasis: a multidisciplinary approch. Trans R Soc Trop Med Hyg 1972, 66:417-437.

43. LoVerde PT: Scanning electron microscop observations on the miracidium of Schistosoma. Int I Parasitol 1975, 5:95-97.

44. Eklu-Natey DT, Wuest J, Swiderski Z, Striebel HP, Huggel H: Comparative scanning electron microscope (SEM) study of miracidia of four human Schistosoma species. Int J Parasitol 1985, 15:33-42.

45. Samuelson JC, Caulfield JP: The cercarial glycocalyx of Schistosoma mansoni. J Cell Biol 1985, 100:1423-1434.

46. Bin Dajem SM, Mostafa OMS: Scanning electron microscopical studies on Schistosoma mansoni cercariae exposed to ultraviolet irradiation. Australian. Journal of Basic and Applied Sciences 2007, 1:776-784.

47. Nargis M, Sato H, Ozaki T, Inaba T, Chisty M, Kamiya H: Cercaricidal effect of hinokitiol on Schistosoma mansoni. Hirosaki Med J 1997, 49:49-57.

48. Chisty MM, Nargis M, Inaba T, Ishita K, Osanai A, Kamiya H: Transmission elecrton microscopy of Schistosoma mansoni cercariae treated with 
hinokitiol ( $\beta$ - thujaplicin), a compound for potential skin application against cercarial penetration. Tohoku J Exp Med 2004, 202:63-67.

49. Jiraungkoorskul W, Sahaphong S, Sobhon P, Riengrojpitak S,

Kangwanrangsan N: Effects of Praziquantel and artesunate on the tegument of adult Schistosoma mekongi harboured in mice. Parasitol Int 2005, 54:177-183.

50. Kaufmann-Kolle P, Fleer EA: Morphological changes of adherent and nonadherent cells by treatment with hexadecylphosphocholine and 1O-octadecyl-2-0-methyl-rac-glycero-3-phosphocholine observed by scanning electron microscopy. Prog Exp Tumor Res 1992, 34:47-58.

51. Rawi SM, El-Gindy HI, Abdel Kader A: I-New possible molluscicide from Calendula micrantha officinalis and Ammi majus. Il-molluscidial physiological and egg lying affect against Biomphalaria alexandrina and Bulinus truncatus snails. J Ecotoxicol Environ Safety 1996, 35:261-267.

52. Tadros MM, Abdel-Khalik SM, Melek F, Gaber NM: Agave angustifolia: A potential source of control agents against Schistosomiasis mansoni. New Egypt J Med 2008, 39:169-176.

53. El-Sherbini GT, Zayed RA, El-Serbini ET: Molluscicidal activity of some Solanum species extracts against the snail Biomphalaria alexandrina. J Parasito Res 2009, 10.1155/2009/474360.

54. Yang G, Li W, Sun L, Wu F, Yang K, Huang Y, Zhou X: Molluscicidal efficacies of different formulations of niclosamide: result of metaanalysis of Chinese literature. Parasit Vectors 2010, 3:84.

doi:10.1186/1756-3305-4-73

Cite this article as: Eissa et al:: Bioactivity of miltefosine against aquatic stages of Schistosoma mansoni, Schistosoma haematobium and their snail hosts, supported by scanning electron microscopy. Parasites \& Vectors 2011 4:73

\section{Submit your next manuscript to BioMed Central and take full advantage of:}

- Convenient online submission

- Thorough peer review

- No space constraints or color figure charges

- Immediate publication on acceptance

- Inclusion in PubMed, CAS, Scopus and Google Scholar

- Research which is freely available for redistribution

Submit your manuscript at www.biomedcentral.com/submit 